\title{
Successful Treatment of Primary Vaginal Papillary Serous Adenocarcinoma Using Chemoradiation Followed by Brachytherapy
}

\author{
M. McCurdy ${ }^{\mathrm{a}}$ N. Zouain ${ }^{\mathrm{b}}$ \\ aDepartment of Medicine, University of North Dakota School of Medicine and \\ Health Sciences, and bepartment of Radiation Oncology, Roger Maris Cancer \\ Center, MeritCare Health System, Fargo, N. Dak., USA
}

\section{Key Words}

Vaginal cancer - Adenocarcinoma - High-dose-rate brachytherapy · Cisplatin . Radiotherapy

\begin{abstract}
Advances in treatment have not recently been reported in rare primary vaginal adenocarcinomas. A 56-year-old woman with a chronic vaginal cyst and possible in utero diethylstilbestrol exposure presented with postmenopausal bleeding. Biopsy of the vagina revealed high-grade papillary serous adenocarcinoma. MRI showed a $6-\mathrm{cm}$ vaginal tumor and $3-\mathrm{cm}$ left inguinal lymph node with metastasis. The patient initially received concurrent cisplatin and radiation. She then received high-dose-rate brachytherapy for further local control. Brachytherapy following external beam radiation with concurrent cisplatin led to clinically undetectable cancer at 24 months with minimal side effects.
\end{abstract}

\section{Introduction}

Vaginal carcinomas account for 1-2\% of all gynecological cancers [1]. Primary therapy for locally invasive disease consists of external and intracavitary or interstitial irradiation, except in selected early cases that may be treated surgically with local excision or with brachytherapy alone. Radical surgery, which may involve partial or total pelvic exenteration, is generally reserved for pelvic recurrence after irradiation and for patients with fistulas at diagnosis. We report a case of stage III primary vaginal papillary serous adenocarcinoma with metastasis to the left inguinal lymph nodes treated definitively with 


\begin{tabular}{|c|c|c|c|}
\hline $\begin{array}{l}\text { Cose Reports in } \\
\text { incisily }\end{array}$ & $\begin{array}{l}\text { Case Rep Oncol 2009;2:97-102 } \\
\text { D0I: } 10.1159 / 000220818\end{array}$ & Published online: June 20, 2009 & \begin{tabular}{|l} 
(c) 2009 S. Karger AG, Basel \\
ISSN 1662-6575 \\
www.karger.com/cro
\end{tabular} \\
\hline
\end{tabular}

external beam radiation concurrent with cisplatin followed by high-dose-rate (HDR) brachytherapy.

\section{Case Report}

A 56-year-old woman with unconfirmed in utero diethylstilbestrol exposure presented in early 2007 with intermittent spotting of a 4-month duration. A vaginal cystic structure was present for 30 years, requiring intermittent aspiration. On vaginal examination, a smooth, non-tender, globular cystic structure was visualized on the right wall of the vagina measuring about 3 to $4 \mathrm{~cm}$ in diameter in the middle third of the vagina. A lymph node $4 \mathrm{~cm}$ in diameter was palpated in the left inguinal area. Vaginal biopsy revealed high-grade papillary serous adenocarcinoma. Metastatic workup included normal endocervical and endometrial biopsies, colonoscopy, mammography, and chest. $2-\left[{ }^{18} \mathrm{~F}\right]$ fluoro2-deoxy-D-glucose positron emission tomography (FDG-PET) scan showed a large, slightly irregular, lobulated hypermetabolic mass near the midline centered slightly to the right $3 \mathrm{~cm}$ in the area of the middle third of the vagina and metastasis to the left inguinal lymph nodes. Computed tomography (CT) showed a $6-\mathrm{cm}$ vaginal mass and $2-\mathrm{cm}$ mass in the left inguinal area. MRI revealed a 6-cm tumor between the bladder and vagina with no invasion of the bladder mucosa and a left inguinal lymph node measuring $3.3 \mathrm{~cm}$ in largest dimension ( $\underline{\text { fig. } 1 \mathrm{a}}$ ). The vaginal incisional biopsy measured $0.7 \times 0.3 \times 0.2$ $\mathrm{cm}$ and was read at an academic medical center as 'grade $2 / 3$ clear cell and focal papillary serous adenocarcinoma with angiolymphatic involvement'. Immunohistochemistry staining showed positive CK7, progesterone receptor, and carcinoembryonic antigen with negative CK20 and estrogen receptor. Clinically, her tumor was stage IIIC by the AJCC staging system, T2 N1 M0 and stage II by the FIGO staging system.

Discussions were held with the patient regarding all treatment options, including possible acute and long-term serious sequelae. Three-dimensional simulation was conducted using a computed tomography simulator (PET-CT Discovery -ST; GE Medical Systems, Waukesha, Wisc., USA). Target volumes were contoured on a Pinnacle system (Phillips Healthcare, Andover, Mass., USA). The patient was treated using 6-MV photons delivered with a 9-field intensity modulated radiotherapy technique to a total dose of $50 \mathrm{~Gy}$ in 25 fractions to the tumor and to $45 \mathrm{~Gy}$ in 25 fractions to the inguinal and pelvic lymph nodes (fig. 2a). She then received an electron boost using $12-\mathrm{MeV}$ photons using a direct field technique to total dose of $30 \mathrm{~Gy}$ in 15 fractions to the $90 \%$ isodose line to the left inguinal lymph nodes. Six cycles of weekly cisplatin at $100 \mathrm{mg} / \mathrm{m}^{2}$ were administered during external beam radiation. HDR brachytherapy delivered 45 Gy to the tumor surface using iridium-192 (fig. 2b). A multiple channel vaginal catheter cylinder (Intracavitary Mould Applicator; Nucletron Inc., Columbia, Md., USA) was inserted into the vaginal cavity. A balloon was inserted on the posterior part of the vaginal catheter. The balloon was inflated with $30 \mathrm{ml}$ of saline with $5 \%$ contrast to position the rectum away from the high dose rate sources and to attenuate the radiation to further protect the posterior wall of the vagina and rectum. Four catheters and 80 dwelling source positions were employed to deliver 5 Gy per treatment session using a HDR unit. The patient experienced a limited amount of side effects during treatment with only grade 2 dermatitis from external beam radiation. MRI performed in between external beam and brachytherapy treatment (fig. 1b) showed partial response of the tumor. Complete response was confirmed by FDG-PET and CT scan 6 months after treatment. At 3, 6 and 18 months, the patient reported improving vaginal discharge at 1 pad per day. She used a dilator to prevent vaginal stenosis. The patient was free of recurrence 24 months after therapy.

\section{Discussion}

Several studies have evaluated external beam radiotherapy for vaginal adenocarcinoma. Two cases of adenocarcinoma were included in a series of 28 primary vaginal cancers treated with external beam radiotherapy and brachytherapy [2]. Frank et al. [3] reported 26 patients with primary vaginal adenocarcinoma treated with external beam radiotherapy and brachytherapy with mostly grade $1-2$ toxicities. The combination of external beam radiotherapy and cis-platinum was described by Samant et al. [4], whose series included 2 cases of adenocarcinoma. In the present case, concurrent cisplatin appeared to sensitize the tumor to radiation since the tumor responded at a lower dose and at a faster rate than expected. Concurrent chemotherapy with irradiation appears to 
significantly enhance radiation effects on cancer and cycling epithelial cells, but it does not appear to proportionately increase late effects in normal tissues [4]. The present case is unique in that we utilized both chemoradiation and brachytherapy to treat vaginal adenocarcinoma.

HDR brachytherapy is an appealing treatment option for vaginal adenocarcinoma. HDR brachytherapy is a technique that delivers radiation to the tumor bed while minimizing dose inaccuracies from internal organ and patient motion [5]. Vaginal HDR brachytherapy has a very low incidence of side effects $[6,7]$ and considering the short treatment time, it appears cost beneficial. Side effects from vaginal brachytherapy for cervical cancer include acute mucositis, proctitis, and cystitis, as well as late proctitis and cystitis, telangiectasia, atrophy, fibrosis and stenosis [8]. In this case, MRI showed only a partial response after external beam treatment concurrent with cisplatin. Complete response was achieved after the addition of brachytherapy. The patient experienced only vaginal discharge during and after radiation therapy and grade 2 dermatitis during external-beam treatment. Despite the tumor's proximity to the bladder, the patient did not develop a fistula between the bladder and vagina. In summary, chemoradiation followed by brachytherapy provided adequate dose to the tumor and lymph nodes for complete clinical response while distributing the dose to prevent severe toxicity. 


\begin{tabular}{c|l|l|l}
$\begin{array}{c}\text { Cose Reports in } \\
\text { Oncolayly }\end{array}$ & $\begin{array}{l}\text { Case Rep Oncol 2009;2:97-102 } \\
\text { D0I: 10.1159/000220818 }\end{array}$ & Published online: June 20, 2009 & $\begin{array}{l}\text { O 2009 S. Karger AG, Basel } \\
\text { ISSN 1662-6575 } \\
\text { www.karger.com/cro }\end{array}$ \\
\hline
\end{tabular}

Fig. 1. Axial T2-weighted pelvic magnetic resonance images. a Two weeks prior to treatment, the 6.0$\mathrm{cm}$ vaginal mass (arrow) and the left inguinal lymph node bed (arrowhead) are prominent. Note the close proximity of the primary tumor to the bladder (block arrow). b Imaging of similar section shows partial response to therapy after external beam radiation treatment and before brachytherapy treatment. The tumor appears to have central necrosis.

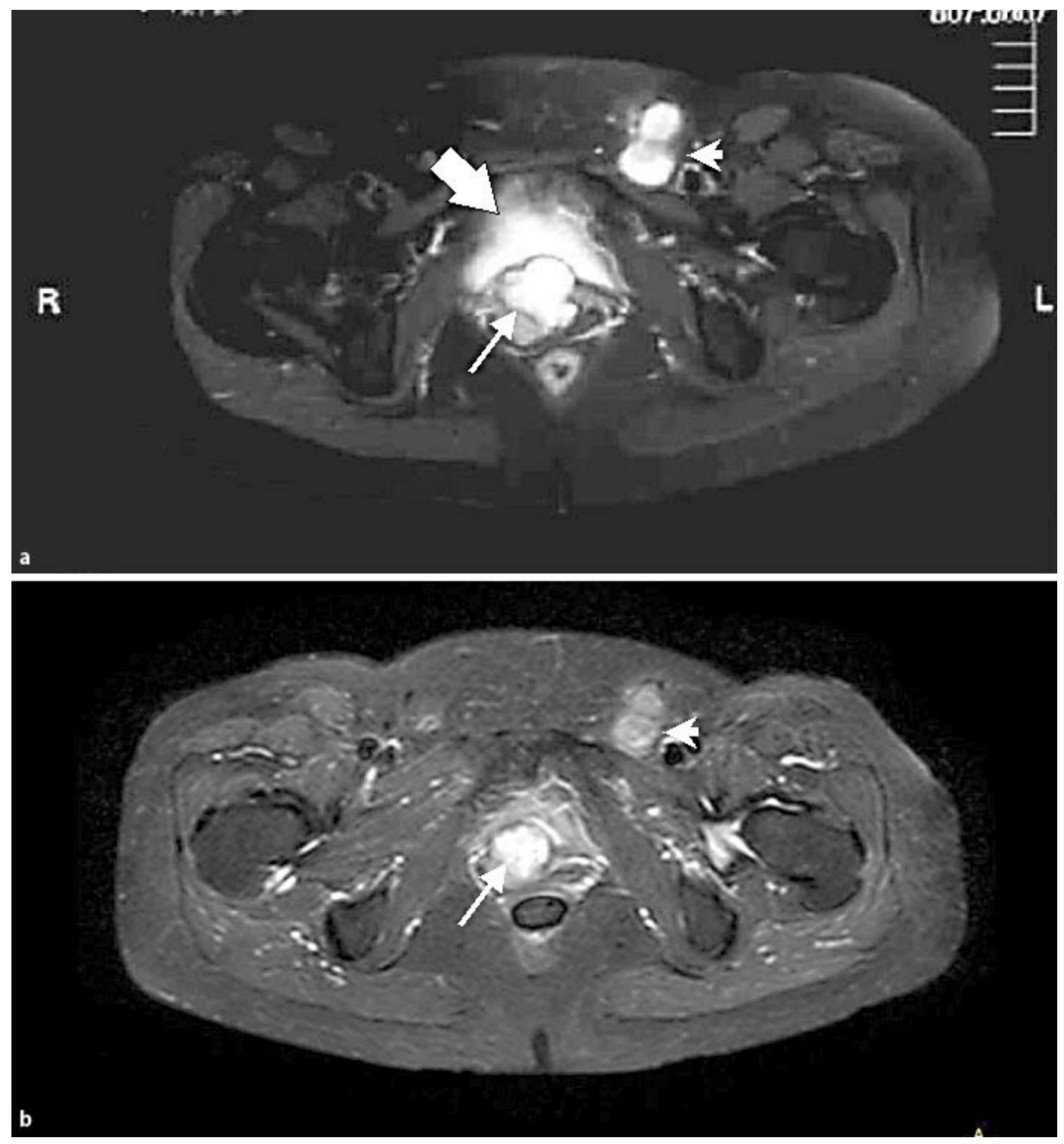




\begin{tabular}{c|l|l|l}
$\begin{array}{c}\text { Cose Reports in } \\
\text { Oncolady }\end{array}$ & $\begin{array}{l}\text { Case Rep Oncol 2009;2:97-102 } \\
\text { D0I: 10.1159/000220818 }\end{array}$ & Published online: June 20, 2009 & $\begin{array}{l}\text { O 2009 S. Karger AG, Basel } \\
\text { ISSN 1662-6575 } \\
\text { www.karger.com/cro }\end{array}$ \\
\hline
\end{tabular}

Fig. 2. Radiation treatment plans. a Intensity-modulated radiotherapy with isodose curves with corresponding dose. A homogeneous distribution of $45 \mathrm{~Gy}$ was achieved to the tumor (solid red shading) and inguinal lymph node beds. b HDR brachytherapy treatment plan for one fraction. Solid red is tumor. Circles are isodose curves in Gy: white $=25$, dark blue $=12.5$, light blue $=10$, yellow $=$ 7.5 , red $=5$, green $=2.5$.

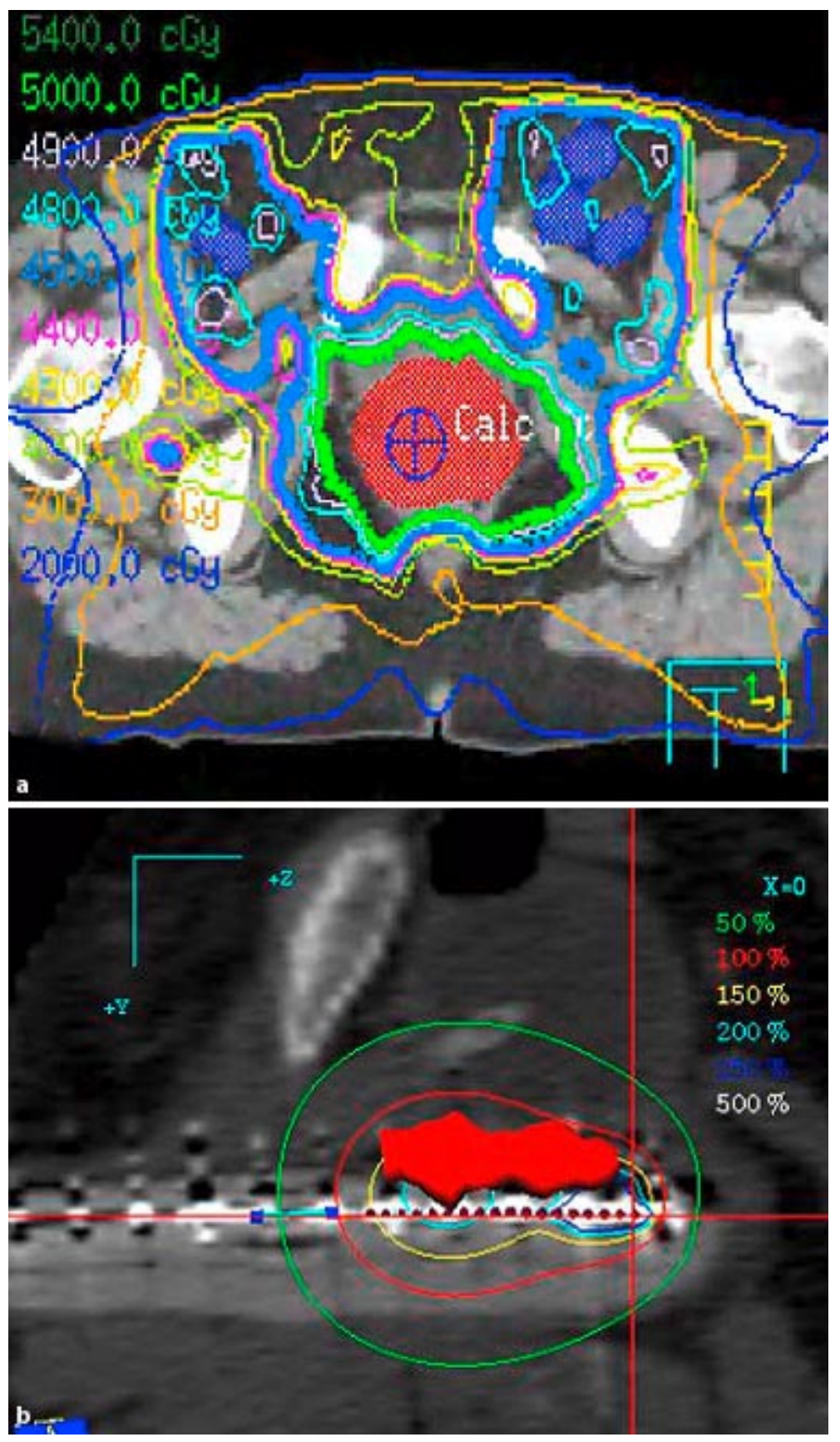




\section{References}

1 Creasman WT, Phillips JL, Menck HR: The national cancer data base report on cancer of the vagina. Cancer 1998;83:1033-1040.

2 Samant R, Tam T, Dahrouge S, E C: Radiotherapy for the treatment of primary vaginal cancer. Radiother Oncol 2005;77:133-136.

3 Frank SJ, Deavers MT, Jhingran A, Bodurka DC, Eifel PJ: Primary adenocarcinoma of the vagina not associated with diethylstilbestrol (DES) exposure. Gynecol Oncol 2007;105:470-474.

4 Samant R, Lau B, E C, Le T, Tam T: Primary vaginal cancer treated with concurrent chemoradiation using Cis-platinum. Int J Radiat Oncol Biol Phys 2007;69:746-750.

5 Gupta AK, Vicini FA, Frazier AI: Iridium 192 transperineal interstitial brachytherapy for locally advanced or recurrent gynecological malignancies. Int J Radiat Oncol Biol Phys 1999;43:1055-1060.

6 6 Eifel PJ, Winter K, Morris M, et al: Pelvic irradiation with concurrent chemotherapy versus pelvic and para-aortic irradiation for high-risk cervical cancer: an update of radiation therapy oncology group trial (RTOG) 90-01. J Clin Oncol 2004;22:872-880.

7 Atahan IL, Ozyar E, Yildiz F, et al: Vaginal high dose rate brachytherapy alone in patients with intermediate- to high-risk stage I endometrial carcinoma after radical surgery. Int J Gynecol Cancer 2008;18:1294-1299 [Epub online].

8 Yildirim G, Ozsaran Z, Yalman D, Kamer S, Aras A: Evaluation of acute and late radiation morbidity in patients with gynaecologic malignancy using the RTOG criteria and Franco-Italian glossary. Eur J Gynaecol Oncol 2008;29:154-157. 